\title{
Assertion, action, and context
}

\section{Robin McKenna ${ }^{1} \cdot$ Michael Hannon $^{2}$ (D}

Received: 24 January 2019 / Accepted: 15 May 2020 / Published online: 25 May 2020

(c) The Author(s) 2020

\begin{abstract}
A common objection to both contextualism and relativism about knowledge ascriptions is that they threaten knowledge norms of assertion and action. Consequently, if there is good reason to accept knowledge norms of assertion or action, there is good reason to reject both contextualism and relativism. In this paper we argue that neither contextualism nor relativism threaten knowledge norms of assertion or action.
\end{abstract}

Keywords Epistemic norms $\cdot$ Assertion $\cdot$ Action $\cdot$ Contextualism $\cdot$ Relativism

\section{Introduction}

Contextualists about knowledge ascriptions think the truth-values of claims of the form "S knows that $p$ " depend on the context of the ascriber (DeRose 2009). In contrast, relativists think the truth-values of such claims depend on the context of the assessor (MacFarlane 2005). What both views have in common is the idea that the truthvalues of knowledge ascriptions are indexed to perspectives, whether of the ascriber or assessor. So contextualism and relativism are both versions of 'perspectivalism':

PERSPECTIVALISM: Where $\mathrm{S}$ is some subject, $p$ some proposition, and i some perspective, "S knows $p$ " is true at perspective i iff (a) $p$ is true (b) $\mathrm{S}$ believes $p$ (c) S's epistemic position with respect to $p$ satisfies the epistemic standards employed in $\mathrm{i}$.

\footnotetext{
$凶$ Michael Hannon

michael.hannon@nottingham.ac.uk

Robin McKenna

rbnmckenna@gmail.com

1 University of Liverpool, Liverpool, UK

2 University of Nottingham, Nottingham, UK
} 
This paper focuses on 'non-subject-centred' perspectivalism, according to which the relevant perspective is either that of whoever utters the knowledge ascription (contextualism) or that of whoever assesses it (relativism). Henceforth, by 'perspectivalism' we mean non-subject-centred perspectivalism.

Many think there are strong ties between knowledge, assertion, and action (Hawthorne and Stanley 2008; Williamson 2000). A common objection to perspectivalism is that it threatens these ties (Hawthorne 2004). If there is good reason to think there are such ties, there is good reason to reject perspectivalism. ${ }^{1}$ Against this common objection, we will argue that perspectivalists can maintain the ties between knowledge, assertion, and action. First, we explain the problem (Sect. 2). Second, we look at two approaches: the 'semantic' approach and the 'pragmatic' approach (Sects. 3, 4). We argue that, while the semantic approach may reduce the scope of the problem, we need to adopt a version of the pragmatic approach if we want to address it fully. Finally, we deal with objections to the pragmatic approach (Sect. 5).

\section{The problem}

Many think that knowledge is the norm of both assertion and action:

ASSERTION: $\mathrm{S}$ knows $p$ iff $\mathrm{S}$ is in a strong enough epistemic position to assert $p .^{2}$

ACTION: $\mathrm{S}$ knows $p$ iff it's appropriate for $\mathrm{S}$ to treat $p$ as a reason for acting (Hawthorne and Stanley 2008).

The perspectivalist has to modify ASSERTION and ACTION to make reference to perspectives. But whose perspective? Imagine Sarah is deciding whether to go into the bank to cash her check now or come back tomorrow (Saturday). ${ }^{3}$ The lines are very long and it is clear there will be a long wait. There's no rush to cash the check, and Sarah has good evidence that the bank is open tomorrow (she remembers it being open on previous Saturdays). Sarah decides to come back tomorrow. Now imagine that Hannah is also deciding whether to go into cash her check or come back tomorrow. While Hannah has the same evidence as Sarah, it is imperative that Hannah cashes her check before Monday. Hannah goes into cash her check.

According to the perspectivalist, Sarah and Hannah both "know" relative to Sarah's perspective, but neither "know" relative to Hannah's perspective. But whether it would be proper for Sarah to assert that the bank is open tomorrow, or treat the proposition that the bank is open as a reason for acting, seems to depend on Sarah's perspective, not Hannah's. That it is imperative that Hannah cashes her check doesn't affect whether Sarah can properly assert or act. Thus, the perspectivalist seems forced to accept the following (DeRose 2009, pp. 99, 263):

\footnotetext{
1 Contra Brown $(2008,2010)$ we assume there are such ties.

2 Williamson (2000: Ch. 11) defends the necessity but not the sufficiency direction of this biconditional. We'll use the biconditional version for the sake of simplicity.

3 For this case see DeRose (2009: Ch. 1).
} 
ASSERTION*: "S knows $p$ " is true at time $\mathrm{t}$ and $\mathrm{S}$ 's perspective $\mathrm{i}$ iff $\mathrm{S}$ is in a strong enough epistemic position to assert $p$ at $\mathrm{t}$.

ACTION*: "S knows $p$ " is true at time $\mathrm{t}$ and $\mathrm{S}$ 's perspective $\mathrm{i}$ iff it's appropriate for $\mathrm{S}$ to treat $p$ as a reason for acting at $\mathrm{t}$.

Consequently, the following may be true (Hawthorne 2004, pp. 85-91):

(1) Hannah: "Sarah doesn't know the bank is open, but she's in a strong enough epistemic position to properly assert that the bank is open."

(2) Sarah: "Hannah knows the bank is open, but she isn't in a strong enough epistemic position to properly assert that the bank is open."

(3) Hannah: "Sarah doesn't know the bank is open, but it's appropriate for her to treat the proposition that the bank is open as a reason for acting."

(4) Sarah: "Hannah knows the bank is open, but it isn't appropriate for her to treat the proposition that the bank is open as a reason for acting."

Each of (1)-(4) have two components: first, a knowledge ascription or denial; and second, an assessment of whether a subject is in a strong enough epistemic position to assert or act. We'll call the first component the 'knowledge component' and the second the 'assertion/action component'. The perspectivalist allows that the truth-values of these components can be indexed to different perspectives. Thus, she has to accept that (1)-(4) may be true.

At this point it is important to clarify how we understand the problem for the perspectivalist. In our view, the problem is not quite that (1)-(4) are inconsistent with the knowledge norms of assertion and action. The perspectivalist clearly cannot accept ASSERTION and ACTION as stated because they implicitly assume that perspectivalism is false. (Maybe it is false, but we can't just build that into our chosen norms of assertion and action!) It is not necessarily a problem for the perspectivalist that she licenses constructions that are inconsistent with ASSERTION and ACTION. At the same time, the perspectivalist - at least if she wants to respect the strength of the case for the knowledge norms of assertion and action-needs to find a viable perspectivalist alternative that accommodates as much of the linguistic data supporting the knowledge norms as possible. Some perspectivalists-like Keith DeRose-think that ASSERTION* and ACTION* are the most promising candidates. The problem, though, is that ASSERTION* and ACTION* license claims like (1)-(4), which are intuitively very odd. As we see it, the task for the perspectivalist is to explain this oddness.

Broadly speaking, there are two approaches that the perspectivalist might take here. First, she could argue that (1)-(4) are actually false (the 'semantic' approach). Second, she could argue that, while (1)-(4) may strictly speaking be true, they could never be properly asserted (the 'pragmatic' approach). We will argue that, while the perspectivalist will struggle to make good on the semantic approach, there is a viable version of the pragmatic approach available. On the version of the pragmatic approach we propose, knowledge ascriptions serve the function of identifying good informants, and (1)-(4) can only perform this function if the truth-values of both the knowledge 
and assertion/action components are indexed to a single perspective. But since the truth-values of both components aren't indexed to a single perspective in (1)-(4), they are unable to perform their function. Consequently, they could never be properly asserted.

We'll start by outlining the semantic approach and explaining why we think it will struggle to deal with the problem. We'll then turn to the pragmatic approach. We finish by discussing several objections to our chosen version of it.

\section{Perspectival flexibility}

Perspectivalists think that the truth-values of knowledge ascriptions are indexed to perspectives, but they allow that speakers and assessors may have purposes that lead them to adopt the subject's perspective as their own. We'll call this 'perspectival flexibility'. Several authors have suggested this idea. John Greco writes:

If we are considering whether we should go to the bank sooner rather than later, then it makes sense to consider what $S$ knows relative to our needs and interests. But if we are considering whether $S$ should go to the bank sooner rather than later, then it makes sense to consider whether $S$ knows relative to his needs and interests. (2008: 425)

If Sarah were helping Hannah decide whether to go into the bank to deposit a check, we would expect Sarah to adopt Hannah's perspective as her own. If she does, Sarah will decide that Hannah doesn't "know" the bank is open tomorrow. The truth-value of Sarah's knowledge ascription will be indexed to Hannah's perspective.

Because of perspectival flexibility, the perspectivalist can argue that the truth-values of the knowledge and assertion/action components need not be indexed to different perspectives. In the situation described above, Sarah would say the following:

(5) Hannah doesn't know that the bank is open tomorrow, and it isn't appropriate for her to assert that it is open tomorrow or treat the proposition that it is open tomorrow as a reason for acting.

In (5) the truth-values of both the knowledge and assertion/action components are indexed to a single perspective, viz. Hannah's. So, due to perspectival flexibility, there will be instances of (2) and (4) where the truth-values of both components are indexed to a single perspective, viz. the subject's. The upshot is that the relevant instances are false. Much the same approach will work for (1) and (3).

The problem is that the appeal to perspectival flexibility only limits the scope of the problem. While speakers and assessors can adopt the subject's perspective as their own, nothing forces speakers and assessors to adopt the subject's perspective as their own. Imagine that Sarah is in no position to help Hannah get her check cashed, and is just offering a dispassionate evaluation of Hannah's situation. Since Sarah can't help, it is hard to see why she would adopt Hannah's perspective as her own or feel under any pressure to do so. In this sort of case, Sarah could truly say the following: 
(6) Hannah knows the bank is open tomorrow, but it isn't appropriate for her to assert that it is open tomorrow, or treat the proposition that it is open tomorrow as a reason for acting, because it's very important to her that it is open.

The perspectivalist can't explain why (6) sounds odd by appeal to perspectival flexibility.

Let's consider another way in which the perspectivalist might try to defend the semantic approach. ${ }^{4}$ In "Contextualism and Knowledge Norms", Worsnip (2017) considers the following relativized version of the knowledge norm of assertion:

KNA-RELATIVIZED: S (epistemically) may assert p iff in S's conversational context, the utterance "I know p" would be true.

This still leads to sentences that sound odd. For example, if we suppose that the subject is in a high-standards context but the ascriber is in a low-standards context, then "I know p" is false in the subject's mouth, and so, by the aforementioned relativized standard, $\mathrm{S}$ is not epistemically permitted to assert $\mathrm{p}$. But since " $\mathrm{S}$ knows $\mathrm{p}$ " is true in the ascriber's context, it should be true for her to say "S knows p, but S may not assert p". That sounds odd.

According to Worsnip, however, the contextualist may reply by utilizing a "doublyrelativized" version of the knowledge norm of assertion, which DeRose calls "KAAR2” (2009, p. 260):

KNA-DOUBLY-RELATIVIZED: An utterance of "S (epistemically) may assert p" in a context $\mathrm{C}$ is true iff the utterance " $\mathrm{S}$ knows $\mathrm{p}$ " in context $\mathrm{C}$ is true.

On this version of the principle, the problematic knowledge ascriptions plausibly come out false. By relativizing both sides of the bi-conditional, Worsnip brings third-person evaluations of the permissibility of assertions and third-person knowledge attributions back together. Thus it can never be true to say "S knows p, but S may not assert p", assuming there is no shift in context during the course of the utterance.

As Worsnip admits, accepting KNA-DOUBLY-RELATIVIZED commits the contextualist to claiming that the semantic value of "may" can vary with the conversational context of the speaker. While Hawthorne (2004, p. 86) seems to think this is a problem, as Worsnip notes, it is (or is at least arguably) semantic orthodoxy that the semantic values of deontic modals depend on the context of utterance (Dowell 2013; Kratzer 1981). So, contra Hawthorne, there is no immediate problem with KNA-DOUBLYRELATIVIZED.

However, as Worsnip goes on to note, the contextualist who accepts KNA-DOUBLYRELATIVIZED is committed to more than just the bare claim that the semantic values of deontic modals depend on the context of utterance. She is committed to the view that the semantic values of deontic modals can depend on the epistemic standards that are operative in the ascriber's context. Is this a problem? Worsnip is inclined to think not:

I do not think this is obviously fatal. What unintuitiveness there may appear to be here can be further cushioned by a move that the contextualist makes in numerous other contexts: namely to insist that the standards that govern a conversational

\footnotetext{
4 Thanks to an anonymous referee for urging us to consider this alternative.
} 
context are not mechanically determined by what is practically at stake for the speaker. Rather, often, the interests and practical situation of the subject can be salient (perhaps via their being salient to the speaker, and part of what she intends to talk with reference to). In contexts where she is talking about what the subject may assert or rely on, she will plausibly often be implicitly talking about what, from the subject's perspective, the subject may assert or rely on. In doing so, she may shift the contextually relevant value of 'knows'. KNA-Doubly-Relativized allows for this (2017, p. 182).

But this means that the defender of KNA-DOUBLY-RELATIVIZED is in a similar position to the contextualist who appeals to perspectival flexibility. While ascribers can adopt the subject's perspective as their own, nothing forces them to do this. Thus, if we return to an earlier example, we have a subject (Hannah) in a high-standards context, and an ascriber (Sarah) in a low-standards context. As before, imagine that Sarah is in no position to help Hannah get her check cashed, and is just offering a dispassionate evaluation of Hannah's situation. Since Sarah can't help, it is hard to see why she would adopt Hannah's perspective as her own or feel under any pressure to do so. In this sort of case, Sarah presumably could truly say:

(7) Hannah knows that the bank is open, and she may assert that it is open.

While the problem is no longer one of divorcing assessments of knowledge and assessments of what a subject may or may not assert, we would submit that it is counter-intuitive that Sarah could truly say that Hannah may assert that the bank is open. Perhaps this isn't a fatal objection. But in the rest of this paper we want to explore the plausibility of the pragmatic approach instead of attempting to make good on the semantic approach.

\section{Perspectival unity}

A recent trend in epistemology has been to focus on the functions or roles of knowledge ascriptions in our socio-linguistic interactions. The guiding idea is that putative facts about the functions of knowledge ascriptions serve as evidence for epistemological theory. We think this research program shows promise. In the remainder of this paper we will appeal to the functions of knowledge ascriptions to show how perspectivalists can deal with (1)-(4), and preserve the links between knowledge, assertion, and action.

While knowledge ascriptions plausibly serve a range of functions, the two most popular and plausible are (a) to identify good or reliable informants (Craig 1990) and (b) to indicate when an inquirer can reasonably terminate inquiry (Kelp 2011; Rysiew 2012)..$^{5}$ These two functions may look distinct, and some people have argued that they are incompatible (e.g. Kelp 2011; Rysiew 2012), but we think they are two sides of the same coin. One common way to reasonably terminate inquiry is by identifying a sufficiently reliable informant who has the information one needs. Attributing knowl-

\footnotetext{
5 Knowledge ascriptions might serve other functions. Our assumption is that identifying reliable informants and terminating inquiry are the most central (common, important) ones. (This becomes important below. See Sect. 4).
} 
edge to someone is a way of expressing the attitude that someone's epistemic position (with respect to a given proposition) is good enough to stop further inquiry. That's precisely what makes such a person a sufficiently reliable informant. Accordingly, to keep things simple we'll limit our attention to the function of identifying reliable informants in what follows. ${ }^{6}$

As shown in the previous section, the appeal to perspectival flexibility can only go so far: it is hard to see how the perspectivalist can avoid accepting that instances of (1)-(4) can be strictly speaking true. But the conditions under which a sentence is true are not necessarily the same as the conditions under which it can be properly asserted. It seems plausible that, if a knowledge ascription has the function of identifying the subject of the ascription as a reliable informant, then one condition for the ascription to be proper is that it serves this function. While there are no doubt many conditions that have to be met in order for a knowledge ascription to perform its characteristic function, one is what we call 'perspectival unity'. The basic idea, which we'll develop in what follows, is that knowledge ascriptions can only perform their characteristic function if the truth-values of both the knowledge and the assertion/action components are indexed to a single perspective. ${ }^{7}$

Let's go through (1)-(4). In (1)-(4), Sarah employs low epistemic standards and Hannah employs high epistemic standards. Take (2) and (4) first. While we want to abstract away from particular details, we'll specify that what's at issue is whether Hannah "knows" that the bank is open tomorrow, and that Hannah has good evidence that the bank is open tomorrow. If Sarah says that Hannah "knows" that the bank is open tomorrow, she identifies Hannah as a reliable informant on the matter of whether the bank is open tomorrow. Think of this as performing a public service. Other people might need this information, and by 'flagging' Hannah as someone with the information Sarah tells them where they can get it. But if Sarah simultaneously says that Hannah "knows" and denies that Hannah is in a good enough epistemic position to assert that the bank is open tomorrow, or to treat the proposition that the bank is open as a reason for acting, that casts doubt on whether Hannah is a reliable informant. Sarah is sending a mixed message, since saying that Hannah is not in a position to assert or act immediately casts doubt on whether Hannah is in fact a reliable informant. Upon hearing what Sarah said, one wonders why Sarah is identifying Hannah as a reliable informant (a "knower") given that she can't properly assert or act. This renders Sarah's knowledge ascription incapable of performing its function. Consequently, Sarah can't properly assert (2) or (4).

Turning to cases (1) and (3), we'll specify that what's at issue is whether Sarah "knows" that the bank is open tomorrow, and that Sarah has good evidence that the bank is open tomorrow. If Hannah denies that Sarah "knows", she signals that Sarah is

\footnotetext{
6 What do we mean when we say that knowledge ascriptions have this function? The thought is that ascribing knowledge is an act, and we perform this act in order to do something, viz. identify someone as a reliable informant on some matter or other. Thus, the function of knowledge ascriptions is a matter of their pragmatics.

7 Notice that we say a 'single' perspective rather than the subject's perspective. Our view is that whether a subject can properly assert or act usually depends on her perspective, but there are cases where it depends on some other perspective. Imagine a case where Hannah approaches Sarah to ask whether the bank is open tomorrow. Once Sarah is aware that it is imperative that Hannah get her check cashed, it would be improper for her to assert that it is open tomorrow based on even very good evidence.
} 
not a sufficiently reliable informant on the matter of whether the bank is open tomorrow. Again, in doing so she is performing a sort of public service. Others around Hannah might need reliable information, and in not identifying Sarah as someone who has it Hannah is suggesting that they can't get it from Sarah. But if Hannah simultaneously denies that Sarah "knows" and says that Sarah is in a good enough epistemic position to assert that the bank is open tomorrow, or to treat the proposition that the bank is open as a reason for acting, that casts doubt on why Sarah isn't a sufficiently reliable informant. Upon hearing what Hannah said, one wonders why Hannah is denying that Sarah is a reliable informant, given that she can properly assert and act. Again, this renders Hannah's knowledge ascription incapable of performing its characteristic function. Consequently, Hannah can't properly assert (1) or (3).

In summary, we have argued that knowledge ascriptions have the characteristic function of identifying reliable informants. In order to serve this function, however, knowledge ascriptions need to exhibit what we called perspectival unity: one can't - as (1)-(4) do-index a knowledge ascription to one perspective, while indexing an assessment of whether the subject can properly assert or act to another, without violating the requirement of perspectival unity.

\section{Objections and replies}

We finish by considering some objections to the pragmatic approach.

First objection: The view that "knows" flags reliable informants does not cohere particularly well with the perspectivalist view we want to defend. One way of putting the worry is as follows. If the semantics of "knows" is perspectival, then how can it be that "knows" flags reliable informants? At best it flags informants that are reliable enough relative to a perspective. But if the semantics really are this complicated, then "knows" isn't suited for identifying reliable informants in the first place.

We take this objection seriously, and one of us has dealt with it at length in another work (Hannon 2013). Put roughly, the response is as follows. If one could combine the view that "knows" flags reliable informants with perspectivalism, one would provide motivation for a sort of perspectivalism on which there is a 'default' epistemic standard that is operative in a wide range of contexts. This default standard is such that any subject who meets it with respect to a proposition $p$ is a reliable informant on the matter of $p$ for many people with diverse interests and purposes. The combination is well motivated because there are certain cases-i.e. cases where speakers and assessors are in unusually pressing practical situations - in which some standard other than the default will be operative. In such cases, we need a standard that is more fitting to the particular practical situation. This gives us a picture on which knowledge ascriptions are stable enough to serve their function, yet there is still room for perspectival variation in the truth-values of knowledge ascriptions. ${ }^{8}$

\footnotetext{
8 This allows us to reply to another objection. You might worry that by combining shifty "knowledge" views with the idea that knowledge ascriptions function to identify reliable informants, we require asserters to check what is at stake for the person to whom they are recommending an informant. This would be a problem because our actual practices clearly do not call for this. But, as above, we think the most plausible shifty views index most (but not all) knowledge ascriptions to a 'default' epistemic standard.
} 
Second objection: On our view, "knowledge" has the characteristic function of identifying reliable informants. So why not identify knowledge with the state of being a sufficiently reliable informant? What motivation is there for the perspectivalist approach?

We have two replies to this objection. First, the characteristic function of knowledge ascriptions might lead one to identify knowledge with the state of being a sufficiently reliable informant, but we want to remain neutral on that issue. Our goal is to show that a characteristic function of knowledge ascriptions can solve a problem for perspectivalism, not to discuss the metaphysics of knowledge.

Second, it would be far too quick to just identify knowing with being a reliable informant. One reason is that while identifying reliable informants is a central function of knowledge ascriptions, it may not apply to every single case in which knowledge is ascribed. For example, consider the case of Robinson Crusoe (or, if you prefer, someone stranded on an island from birth). Robinson Crusoe knew any number of things (e.g. that he could eat certain fruits) but he wasn't much good as an informant. Or, to take another example, consider the mafia boss. She knows a number of things about illegal mafia activity, but she isn't much use as an informant because she isn't inclined to talk to the police. So, while we are officially neutral on the metaphysics, we don't think you can just equate knowing with being a reliable informant without further argument.

Third objection: The idea behind the pragmatic approach is that, while (1)-(4) may strictly speaking be true, they could never be properly asserted. But if we accept a perspectivalist variant of the knowledge norm of assertion, then (1)-(4) will be properly asserted just in case they are known. Unless we deny that anyone can ever know (1)-(4), the pragmatic approach is doomed to fail.

This is a good point, but it isn't damaging to us. Defenders of the knowledge norm of assertion do not (or at least should not) claim that any assertion that satisfies the knowledge norm is thereby proper all-things-considered or simpliciter. For example, consider someone who has hidden some fugitives in the basement in order to help them evade enemy soldiers. If the enemy knocks on her door and asks where the fugitives are, it would be improper all-things-considered for her to assert that the fugitives are in the basement, even though she knows that they are. Indeed, it would be entirely proper all-things-considered for her to assert that she has no idea where the fugitives are. Such cases don't tell against the knowledge norm of assertion because it isn't a norm that tells us the conditions an assertion has to meet in order to be proper allthings-considered. So when we say that on our view no assertion of (1)-(4) could be proper, we mean proper all-things-considered, not proper so far as the knowledge norm of assertion goes.

Fourth objection: Take case (2). We have said that Sarah cannot properly assert "Hannah knows the bank is open, but it isn't appropriate for her to assert that it is open". Put roughly, this is because no assertion of (2) could serve to identify Hannah as a reliable informant, since whether Hannah is a reliable informant is instantly cast into doubt by Sarah's claim that Hannah can't appropriately assert. But why does noting that Hannah can't appropriately assert cast doubt on whether she is a reliable informant? Let's imagine, first, that Sarah and her audience are fully aware that Hannah is in an unusually pressing practical situation; second, that Sarah and her audience are 
not in a high stakes situation; and third, that they are interested in whether the bank is open on Saturday, and so in whether Hannah is a good informant as to whether it is open. In this case, why would it cast doubt on Hannah's reliability as an informant if Sarah were to note that Hannah couldn't properly assert that the bank is open?

The term "knowledge" plays a complex role in folk epistemological practices. On our hypothesis, "knowledge" is characteristically used to identify reliable informants to an audience. Moreover, there is a strong intuitive connection between appropriate assertion and "knowledge". Thus, if Sarah says that it isn't appropriate for Hannah to assert that the bank is open, a natural way to hear this criticism is that Hannah wasn't reliable enough to assert this. This isn't to say that Hannah is in fact not reliable enough for Sarah's purposes. If, as we are imagining, the stakes are low for Sarah, then Hannah's information may be good enough for Sarah, even though Hannah can't properly assert or act on that information herself. Nevertheless, given the tight connection between assertion and reliability in our epistemic evaluations, it is not surprising that to deny that someone may properly assert $p$ casts doubt on their reliability as an informant on whether $p$. An intuitive connection between assertion and reliability is broken.

Thus, strictly speaking, we hold that, while there are good reasons why Sarah's assertion that Hannah knows but can't assert that the bank will be open sounds odd, this reaction is based on a mistake. The assertion sounds odd because we take it that, if Sarah can't assert some proposition, then she can't be a reliable informant with respect to this proposition. But this is wrong. It could be that Sarah is reliable enough for our purposes, but not for her own. ${ }^{9}$

We hold that part of the reason why (1)-(4) strike us as so odd is a sort of ignorance. But this ignorance is a little different from the sort of ignorance commonly posited by contextualists (see DeRose 2009: Ch. 6). Contextualists tend to emphasise that we are ignorant of the context-sensitivity of the word "knows" and its cognates. But the sort of ignorance we have in mind isn't about the context-sensitivity of the word "knows". On our view, following Edward Craig, knowledge ascriptions serve the purpose of identifying reliable informants. The basic idea is that the central reason why we have a practice of ascribing knowledge to others is in order to meet a basic need that we have to identify reliable sources of information. Given this, it is no surprise that, when we hear someone saying something that seems to cast doubt the reliability of a potential informant, we take this to mean that they are in fact not a reliable informant. But-as we will discuss below-knowledge ascriptions can sometimes serve other functions besides identifying good informants. When they do so, we are mistaken about the intent of the knowledge ascription, and so it might strike us as odd when in fact it makes perfect sense. After all, Hannah is a reliable informant, even though she's not in a strong enough epistemic position to assert or act. ${ }^{10}$

\footnotetext{
9 Thanks to an anonymous reviewer for urging us to clarify this aspect of our view.

10 An anonymous reviewer suggested that, on our view, the inference from "S can't properly assert that/act on p" to "S isn't a reliable informant about p" is a sort of "heuristic proxy". While the inference generally holds, it fails in certain cases. But it is easily explicable why we make it: it is cognitively cheap. Gerken (2017) defends this sort of view of the knowledge norms themselves, so while our view is perhaps analogous to Gerken's, it is importantly different because we are not committed to the view that the knowledge norms (or rather contextualised versions of them) are mere heuristic proxies.
} 
Fifth objection: Take case (3). Our view is that Hannah cannot properly assert "Sarah doesn't know the bank is open, but it is appropriate for her to act on the basis that it is open". Again, this is because no assertion of (3) could serve to signal that Sarah isn't a sufficiently reliable informant (in claiming that she can act, Hannah suggests that Sarah is sufficiently reliable after all). But why doesn't Hannah's noting that Sarah can act not just cancel any implicature that Sarah is not a sufficiently reliable informant? If it can, why need assertions of (3) be improper? After all, there's nothing improper about cancelling a conversational implicature. More generally, we have accepted that there are situations where knowledge ascriptions don't serve their characteristic function of identifying reliable informants. In such situations, wouldn't any conversational implicature that the subject of the ascription is (or isn't) a reliable informant be cancelled, and so our explanation of the oddity of claims like (1)-(4) wouldn't go through?

First, let us just register that the 'cancellability test' for conversational implicatures isn't universally accepted (see, for instance, Weiner 2006). Second, and more importantly, it is not part of our view that knowledge ascriptions conversationally implicate that the subject of the ascription is a reliable informant or that knowledge denials implicate that the subject isn't a sufficiently reliable informant. While we think of the function of "knows" as a matter of the pragmatics of knowledge ascriptions, not all pragmatics concerns conversational implicature. A better way of thinking about the function of "knows" is in terms of the illocutionary force of knowledge ascriptions (recall fn. 6). To take an analogy, a central function of "good" claims—claims of the form " $x$ is good" - is to commend or otherwise signal approval of persons, deeds and courses of action. One way of thinking of this is in terms of the illocutionary force of "good" claims. Put roughly, in saying that something is "good" I do something, viz. commend or signal approval of it. Similarly, in saying that $S$ "knows" $p$ I do something, viz. identify or recommend $\mathrm{S}$ as a reliable informant on the matter of $p$.

Finally, this leaves the question of what we say about situations where knowledge ascriptions don't serve their characteristic functions. Take the case of Robinson Crusoe, but ignore the part of the story where he makes contact with other humans. Presumably Robinson Crusoe can truly be said to know certain things; e.g. that the berries in the bush are edible. But it seems a bit of a stretch to say that, if we were to ascribe knowledge to Crusoe, we would be identifying him as a reliable informant. Who, exactly, is he a reliable informant for? This suggests a problem. Imagine a situation where it is imperative for Crusoe that he not make a mistake about whether the berries he has picked are poisonous or not. He has eaten berries that look like these berries before and was fine, but he's unsure. It seems plausible that, by the perspectivalist's lights, he doesn't "know" that the berries aren't poisonous relative to the standards operative in his perspective, and so cannot assert that they aren't poisonous or treat the proposition that they aren't poisonous as a reason for acting (e.g. eating them). But, equally, it seems plausible that he does "know" that they aren't poisonous relative to the standards operative in other perspectives - those where whether the berries are poisonous or not isn't a pressing practical question. So the following seems to be true in this perspective: 
(8) Crusoe knows that the berries aren't poisonous, but it isn't appropriate for him to assert that they aren't poisonous, or treat this proposition as a reason for acting.

But we cannot explain the oddness of (8) in terms of the function of identifying reliable informants because - as we have admitted - ascriptions of knowledge to Crusoe don't seem to serve this function.

There are two routes that we might take in response to this objection. Because we aren't settled on which route to take, we will merely outline each and leave it up to the reader to decide which is more plausible. First, we could argue that, in fact, there is a sense in which all knowledge ascriptions serve the characteristic function of identifying reliable informants (for this line see Hannon 2013, 2019; McKenna 2013). The basic idea would be that, while all knowledge ascriptions serve to identify reliable informants, they need not all serve to identify reliable informants for the present audience. To take a different example, consider a claim like "Galileo knew that the Earth orbits the sun". This can't be read as identifying Galileo as a reliable informant on the Earth's orbit for us; astronomy has gone far beyond Galileo. But it can be read as identifying Galileo as a reliable informant on the Earth's orbit for a past audience. Taken this way, the claim amounts to something like "In 1616, Galileo was a good informant about whether the Earth orbits the sun".

Can something similar work with the Crusoe case? We think that it can. We can read a claim like "Crusoe knows that the berries aren't poisonous" as identifying him as a reliable informant for a hypothetical audience. We can then give a similar explanation of the oddness of (8) to that given of (1)-(4). The problem with (8) is that it sends out a mixed signal to this same hypothetical audience. On the one hand, it identifies Crusoe as a reliable informant for the hypothetical audience; on the other, it casts doubt on his reliability.

The second route is to reiterate a point we made in response to the fourth objection. Our practice of knowledge ascription gains its point and purpose in a particular social context: the identification of reliable informants. This means that, when we consider knowledge ascriptions in rather different social contexts- such as the context of a lone individual who is in no position to be an informant for anyone-our intuitions can be regarded as less probative. Maybe (8) does strike us as odd. But given how unusual the context is, does this much matter?

\section{Concluding remarks}

A common objection to both contextualism and relativism is that they threaten the ties between knowledge, assertion, and action. As we have seen, the problem is not that defenders of these views can't defend versions of the knowledge norms of assertion and action. Rather, the problem is that they are unable to explain the oddity of (1)-(4). But, as we have argued, while instances of (1)-(4) may be true, they could never be properly asserted. We take this to show 
that, as far as contextualism and relativism are concerned, the ties remain in place. $^{11}$

Open Access This article is licensed under a Creative Commons Attribution 4.0 International License, which permits use, sharing, adaptation, distribution and reproduction in any medium or format, as long as you give appropriate credit to the original author(s) and the source, provide a link to the Creative Commons licence, and indicate if changes were made. The images or other third party material in this article are included in the article's Creative Commons licence, unless indicated otherwise in a credit line to the material. If material is not included in the article's Creative Commons licence and your intended use is not permitted by statutory regulation or exceeds the permitted use, you will need to obtain permission directly from the copyright holder. To view a copy of this licence, visit http://creativecommons.org/licenses/by/4.0/.

\section{References}

Brown, J. (2008). Knowledge and practical reason. Philosophy Compass, 3(6), 1135-1152.

Brown, J. (2010). Knowledge and assertion. Philosophy and Phenomenological Research, 81(3), 549-566.

Craig, E. (1990). Knowledge and the state of nature: An essay in conceptual synthesis. Oxford: Oxford University Press.

DeRose, K. (2009). The case for contextualism: Knowledge, skepticism and context (Vol. 1). Oxford: Clarendon.

Dowell, J. (2013). Flexible contextualism about deontic modals: A puzzle about information-sensitivity. Inquiry, 56(2-3), 149-178.

Gerken, M. (2017). Folk epistemology: How we think and talk about knowledge. Oxford: Oxford University Press.

Greco, J. (2008). What's wrong with contextualism? Philosophical Quarterly, 58(232), 416-436.

Hannon, M. (2013). The practical origins of epistemic contextualism. Erkenntnis, 78(4), 899-919.

Hannon, M. (2019). What's the point of knowledge?. New York, NY: Oxford University Press.

Hawthorne, J. (2004). Knowledge and lotteries. Oxford: Oxford University Press.

Hawthorne, J., \& Stanley, J. (2008). Knowledge and action. Journal of Philosophy, 105(10), 571-590.

Kelp, C. (2011). What's the point of "knowledge" anyway? Episteme, 8, 53-66.

Kratzer, A. (1981). The notional category of modality. In H. Eikmeyer \& H. Rieser (Eds.), Words, worlds, and contexts (pp. 38-74). Berlin: de Gruyter.

MacFarlane, J. (2005). The assessment sensitivity of knowledge attributions. Oxford Studies in Epistemology, 1, 197-233.

McKenna, R. (2013). "Knowledge" ascriptions, social roles and semantics. Episteme, 10(4), 335-350.

Rysiew, P. (2012). Epistemic scorekeeping. In J. Brown \& M. Gerken (Eds.), Knowledge ascriptions (pp. 270-293). Oxford: Oxford University Press.

Weiner, M. (2006). Are All conversational implicatures cancellable? Analysis, 66(290), 127-130.

Williamson, T. (2000). Knowledge and its limits. Oxford: Oxford University Press.

Worsnip, A. (2017). Contextualism and knowledge norms. In J. J. Ichikawa (Ed.), The Routledge handbook of epistemic contextualism (pp. 177-189). London: Routledge.

Publisher's Note Springer Nature remains neutral with regard to jurisdictional claims in published maps and institutional affiliations.

\footnotetext{
11 Thanks to several anonymous referees, Davide Fassio, and Nick Hughes for their comments on earlier versions of this paper.
} 